\title{
Água e política: atores, instituições \\ e poder nos Organismos Colegiados de Bacia Hidrográfica no Brasil
}

\author{
Hildelano Delanusse Theodoro' \\ I Grupo de Pesquisa em Governança de Águas; Universidade Estadual do Norte Fluminense (UENF); \\ Campos dos Goytacases, RJ, Brasil. \\ E-mail: hildelano@yahoo.com
}

Recebido em: 03 Jun. 2018. Aceito: 19 fev. 2019. DOI: http://dx.doi.org/I0.2I674/2448-0479.5।.79-82

\section{Resumo}

A resenha trata sobre as principais discussões existentes no livro organizado por Rebecca Neaera Abers, professora do Instituto de Ciência Política da Universidade de Brasília, e que tratam sobre a gestão de recursos hídricos no Brasil a partir de um estudo de 14 comitês e 04 consórcios responsável por diversas bacias hidrográficas no território nacional, através do "Projeto Marca d'Água". Suas questões se referem a salientar quais os obstáculos e potencialidades existentes ao desenvolvimento de processos institucionais e sociais colaborativos entre stakeholders com interesses e realidades tão diferentes. Com a análise dos dados obtidos, o livro se torna referência para o entendimento do perfil dos organismos colegiados de bacia hidrográfica existentes no país atualmente.

Palavras-chave: Políticas Públicas. Gestão de Recursos Hídricos. Gestão Participativa; Gestão Ambiental.

\section{Abstract}

This review comes on the main existing discussions from the book edited by Rebecca Neaera Abers, teacher at the Institute of Political Science, University of Brasilia, and that deals with the management of water resources in Brazil from a study of 14 committees and 04 consortiums responsible over several river basins in the country, through the project "Marca d'Água (Watermark)". The questions are to emphasize which obstacles and potentialities for the development of institutional and social collaborative processes between stakeholders with different interests and realities. With the data analysis, the book becomes a reference for understanding the profile of watershed committees in the country these days.

Keywords: Public Policy. Water Resources Management. Participatory Management. Environmental Management.

\section{Introdução}

\section{“Instituições Hídricas em Análise Comparada"}

Concebido a partir dos extensos resultados obtidos em pesquisa realizada em quatorze comitês de bacia hidrográfica e quatro consórcios intermunicipais de bacia, o livro intitulado "Água e política: atores, instituições e poder nos Organismos Colegiados de Bacia Hidrográfica no Brasil”, de organização da professora do Instituto de Ciência Política da Universidade de Brasília, Rebecca Neaera Abers, deve ser entendido como uma oportunidade destacada de se poder analisar comparativa o cenário de construção das políticas públicas vinculadas à gestão hídrica e ambiental no país. 
Sendo oriundo dos trabalhos desempenhados pelo "Projeto Marca d'Água", que é foi concebida à época como uma rede de pesquisadores que estudaram o andamento institucional, político e social dos organismos de bacia hidrográfica em várias regiões do Brasil, o livro cria um cenário das principais mudanças, entraves e possibilidades colocadas aos mesmos. É uma leitura que favore o aprendizado sobre processos sociais e institucionais em cenários de complexidade e capacidades de respostas diferentes dentro do sistema de recursos hídricos brasileiro.

\section{Materiais e Métodos}

Mesmo sendo um trabalho publicado no ano de 2010, chama atenção sua atualidade em termos de análise metodológica e das discussões em si, uma vez que os problemas de gestão hídrica ainda são muito vinculados aos seus arranjos institucionais e políticos para a tomada de decisões. Ao se pensar que alguns anos se passaram desde seu lançamento e que as questões das categorias sociais e modelos de gestão empregados ainda enfrentam situação de desgates e desafios similares na construção de uma agenda pública hídrica, a excelência do livro se dá muito pela organização de sua base de dados e, consequentemente, de suas correlações analíticas. E tal trabalho se encontra estruturado em suas 246 páginas construídas a partir de diversos olhares e que, além do Prefácio de Kathryn Hochstetler (professora de Ciência Política na Universidade de Waterloo, Canadá) e da Introdução da própria organizadora, se encontra dividido em três partes, de acordo com as perspectivas de suas discussões:

I) Parte I "Os atores: formação, experiência e visão de mundo dos participantes de organismos de bacia" - dois textos;

2) Parte 2

"As instituições: o papel dos governos municipais e estaduais" - dois textos;

3) Parte 3

"Os processos: a dinâmica da participação nos comitês" - três textos.

Por sua própria divisão se percebe, inerentemente, que o texto tenta abarcar ao máximo as principais características necessárias ao melhor entendimento sobre a dinâmica dos organismos de bacia hidrográfica, sem se ater a um formato de análise clássica entre Estado/Sociedade Civil/Setor Privado. Ao contrário, o que se percebe é um cuidado em se demonstrar a complexidade interacional existente entre os atores, suas instituições e seus processos consequentes, tal como colocado nos títulos de suas seções e nas análises internas dos textos.

Esse direcionamento de interpretação se deve menos ao fato de busca por uma originalidade discurso (o que também ocorre) do que pela real demanda de novas abordagens metodológicas onde processos de resolução de interesses e conflitos entre multi-stakeholders possam ser melhor explicitados. Nesta direção, vale ressaltar o reconhecimento que o livro dá ao fato de que "[...] comitês e consórcios de bacia hidrográfica são mais representativos e deliberativos do que muitos supunham, mas também argumenta que o contexto institucional mais amplo precisa mudar, para que esses colegiados consigam realizar seu potencial." (p. II).

\section{Resultados e Discussão}

Essas mudanças tidas como essenciais ao melhoramento das atividades relacionadas à gestão dos recursos hídricos no país ou, ao menos, nas inúmeras bacias estudadas, poderiam então ser encaradas sob perspectivas tanto da inclusão e consolidação de atores sociais e institucionais, como da incorporação de estratégias de gestão de conhecimentos técnicos e administrativos que por vezes não foram considerados nos tradicionais modelos de gerenciamento ambiental.

Por isso mesmo é que os autores discutem sobre vários obstáculos para que uma cultura de trabalho colaborativo aconteça, sendo que a hipótese geral que os mesmos se debatem no trabalho é justamente, segundo Abers, as limitações se encontram na estrutura dos órgãos de Estado vinculados com os organismos de bacia. 
A realidade é que a questão da gestão dos recursos hídricos não pode ser entendida de maneira uniforme ou unilateral, uma vez que, tal como demonstra o livro, o nível de desenvolvimento e envolvimento dos atores e instituições envolvidas é muito distinto. Assim, fatores que são influenciadores (porém não definidores) da capacidade de resolução dos comitês e consórcios para suas questões recorrentes, podem e dever ser melhor identificados e desenvolvidos, a ver:

a) Os membros dos organismos de bacia estudados tem um alto nível de formação, principalmente “... entre os representantes dos poderes públicos federal e estadual, e o mais baixo é observado entre os pequenos produtores" (p. 48 e 62) e possuem perfil multidisciplinar (p. 54);

b) A questão de gênero e sua importância dentro dos comitês ainda é negligenciada e necessidade de mais estudos, uma vez que a pesquisa indicou que as mulheres ainda continuam em um "...papel de suporte, enquanto o poder decisório continua nas mãos dos homens." (p. 32);

c) Existe uma confiabilidade maior dos entrevistados pela pesquisa na competência dos governos municipais em relação ao governo federal e estadual, consecutivamente (p. II5), mesmo sendo considerados, ao mesmo tempo, como um dos principais criadores de obstáculos ao bom funcionamento de comitês (p. I19);

d) Quem costuma mais se expressar nas plenárias são os representantes do Poder Público Federal (67\%), a Sociedade Civil (63\%) e o Poder Público Estadual (54\%), respectivamente, sendo o Poder Público Municipal o menos disposto a fazê-lo (p. 126);

e) O Conhecimento Técnico-Científico para a tomada de decisão pelos stakeholders deve ser cada vez mais considerado como um instrumento de apoio para a valorização econômica da água, como também para a contribuição na prevenção e contingência de riscos de acidentes ambientais, por exemplo (p. 196).

A partir destes principais aspectos salientados anteriormente (e alguns outros a partir do tipo de abordagem dada) o livro destaca algo importante de ser discutido dentro dos organismos de bacia, que "[...] nossas instituições públicas não estão preparadas para realizar articulação governamental, nem para aceitar facilmente as decisões realizadas nos colegiados." (p. 147).

E talvez aí se encontre mais um valor da leitura deste livro, que é o fato de se evidenciar que não são as pessoas que estão inadequadas em termos de educação, tempo de dedicação ou experiência sobre recursos hídricos; elas podem estar inadequadas em suas ações em termos de representação e planejamento de interação colaborativa. Tanto que os autores salientam que a literatura que destaca a participação de forma constante nos organismos de bacia hidrográfica tendem a enxergar esta dotada de "[...] três funções: i) promover a inclusão política; ii) estimular processo deliberativos interativos; iii) aumentar o controle da sociedade sobre o Estado." (p. 216).

A significação então destas funções nada mais seria do que poder criar espaços onde a interlocução de longo prazo entre Estado (e suas subdivisões organizacionais), Sociedade Civil (e suas variadas tendências ideológicas/políticas) e Mercado (e suas demandas/consumo de recursos hídricos em níveis multivariados) possa ocorrer, porém com a possibilidade da criação, também, de "produtos" tangíveis de serem avaliados, inteligíveis e aplicáveis.

\section{Considerações finais}

Finalmente, seria válido se enfatizar que o trabalho desenvolvido no livro se torna uma leitura de importância para todos aqueles iniciados ou em busca de um conhecimento maior sobre o cenário da gestão dos recursos hídricos no Brasil, principalmente a partir dos anos 2000. E isto se dá pelo fato de que os autores enfatizaram que as questões técnicas relacionadas à gestão da água são relevantes, mas não são suficientes para explicarem contextos de conflitos que são, em essência, políticos. 
Tal postura é fundamental para um amadurecimento tanto das discussões intelectuais vinculadas ao tema como, principalmente, dos tomadores de decisão que se encontram com a grande responsabilidade de tornar a gestão dos recursos hídricos, de forma integrada, uma realidade, e não apenas um paradigma, nos próximos anos.

Nesse sentido, os apontamentos realizados pela pesquisadora e sua equipe demonstra a necessidade crescente de, primeiramente, que os estudos sobre recursos hídricos sejam cada vez mais complexos em termos de coleta e análises de dados e, posteriormente, que as análises daí advindas consigam mostram caminhos para que atores, instituições e poder nos organismos colegiados de bacia hidrográfica brasileiros sejam melhor entendidos e aperfeiçoados.

\section{Agradecimentos}

Esta resenha foi desenvolvida durante período de doutoramento em Saneamento, Meio Ambiente e Recursos Hídricos, na Universidade Federal de Minas Gerais (UFMG) com bolsa de pesquisa oriunda da Coordenação de Aperfeiçoamento de Pessoal de Nível Superior (CAPES).

\section{Referências}

ABERS, R.N. (Org.). Água e política: atores, instituições e poder nos Organismos Colegiados de Bacia Hidrográfica no Brasil. São Paulo: Annablume, 2010. 